\title{
BMJ Open Evaluating the knowledge, attitudes and practices of the UAE community on microbiota composition and the main factors affecting it: a cross-sectional study
}

\author{
Hiba Jawdat Barqawi (ID , 'Saryia Farouk Adra, ${ }^{2}$ Hiba Riad Ramzi, ${ }^{2}$ \\ Mahmoud Alaa Abouaggour, ${ }^{2}$ Shamma Khamis Almehairi ${ }^{2}$
}

To cite: Barqawi HJ, Adra SF, Ramzi HR, et al. Evaluating the knowledge, attitudes and practices of the UAE community on microbiota composition and the main factors affecting it: a cross-sectional study. BMJ Open 2021;11:e047869. doi:10.1136/ bmjopen-2020-047869

- Prepublication history for this paper is available online. To view these files, please visit the journal online (http://dx.doi. org/10.1136/bmjopen-2020047869).

HJB and SFA contributed equally.

Received 14 December 2020 Accepted 04 August 2021

Check for updates

(c) Author(s) (or their employer(s)) 2021. Re-use permitted under CC BY-NC. No commercial re-use. See rights and permissions. Published by BMJ.

${ }^{1}$ Department of Clinical Sciences, College of Medicine, University of Sharjah, Sharjah, UAE

${ }^{2}$ College of Medicine, University of Sharjah, Sharjah, UAE

Correspondence to Hiba Jawdat Barqawi; hbarqawi@sharjah.ac.ae

\section{ABSTRACT}

Objectives This study aims to explore the knowledge, attitudes and practices (KAP) of the population in the United Arab Emirates (UAE) regarding microbiota and the main factors affecting its composition.

Design/setting A cross-sectional study, using a selfadministered questionnaire, was conducted from May 2018 to September 2018, recruiting participants in public venues via convenience sampling.

Participants UAE residents (aged 18 years and above) who spoke either Arabic or English.

Results 419 responses were completed and analysed using SPSS V.24. Only $29.3 \%(n=94)$ of the participants who defined microbiota correctly had good knowledge. There was a significant difference in knowledge among different age groups $(p=0.004)$ and educational levels $(p<0.001)$. Multiple linear regression (MLR) model indicated that being a university student and a healthcare professional $(\mathrm{HCP})$ are the only significant predictors regarding microbiota knowledge $(p=0.014$ and $p<0.001$, respectively). Of the respondents who claimed to be aware of probiotics, only $9.1 \%(n=15)$ exhibited good knowledge. MLR model showed that being a postgraduate and an HCP are the only significant predictors for probiotics knowledge $(\mathrm{p}=0.016$ and $\mathrm{p}<0.001$, respectively). $42.4 \%(\mathrm{n}=143)$ and $34.6 \%(n=28)$ of the non-medical and HCP participants, respectively, use antibiotics without a prescription. None of the respondents, with or without a medical background, demonstrated good attitudes and practices toward the use of antibiotics.

Conclusion Despite the fact that the participants had a basic understanding of microbiota and probiotics, the overall knowledge was substandard. Additionally, the respondents engaged in improper practices that alter the microbiota composition, especially via antibiotics misuse. Campaigns should target the general population as well as HCPs to upheave their overall KAP.

\section{INTRODUCTION}

The human body is a host to a wide variety of microorganisms that outnumber the human body cells; recent research estimates that for
Strengths and limitations of this study

- A pilot study was conducted, and standardisation sessions were held to ensure a consistent and uniform data collection process.

- The participants in this study were randomly selected and the questionnaires were self-administered after explaining the aims of the study to the participants and providing them with an information sheet.

- Convenience sampling was used in this study, which could affect the generalisability of the results.

- The study included only the three largest cities of the UAE: Abu Dhabi, Dubai and Sharjah; hence, the results might not be representing the UAE population wholly.

- The correlation between socioeconomic status and the participants' perception was not explored.

every human cell there are 1.3 bacterial cells in our body; yet they coexist in a dynamic fashion. This estimate does not consider the viruses, fungi and phage that exist in our body, which equal or outnumber the bacterial estimate. These microorganisms, known as microbiota or microflora, share a harmonious relationship with human body cells, in which both depend on the other for survival. ${ }^{1}$

The microbiota in the human body confers immunity against various diseases by acting as a physical barrier against pathogens, preventing their colonisation by consuming the available nutrients and producing antimicrobial substances. The gastrointestinal tract (GIT) microbiota consists of more than 35000 bacterial species, the majority of which are obligate anaerobes. ${ }^{2}$

The composition of the microflora is host specific and subject to alterations throughout the individual's life. ${ }^{2}$ As such, each person's microbiotic composition is unique, and 
influenced by factors such as age, sex, diet, hygiene, environment and antibiotic use. ${ }^{3}$ Furthermore, imbalances in the GIT microbiota are associated with obesity and several diseases, such as type 2 diabetes mellitus. ${ }^{45}$ It is estimated that around $40 \%$ of the UAE population are either prediabetic or diabetic. ${ }^{6}$

Using external supplementation of beneficial microorganisms, in the form of probiotics, helps to preserve and restore the proper intestinal microflora balance. ${ }^{7}$ The WHO defines probiotics as 'live microorganisms which when administered in adequate amounts confer a health benefit on the host'. ${ }^{8}$ Probiotics are available in the form of food, beverages and drugs. Moreover, probiotic products contain different strains of beneficial bacteria such as Lactobacillus and Bifidobacterium that can colonise the GIT achieving a healthier balance of microflora. ${ }^{9}$

Additionally, probiotics have been shown to have either prophylactic or adjuvant therapeutic effects on a vast spectrum of infective and non-infective diseases, such as inflammatory bowel disease (IBD), irritable bowel syndrome, Helicobacter pylori infection, gastroenteritis, respiratory tract infections, lactose intolerance, oral candidiasis, urinary tract infection, colon cancer and breast cancer. ${ }^{10-18}$ Furthermore, probiotics have been attributed to lowering blood cholesterol levels and treating psychiatric illnesses. ${ }^{19}$

In the literature, misuse of antibiotics is well documented; it leads to a disruption in the GIT microbiota composition and a state of dysbiosis. ${ }^{20}{ }^{21}$ Recent studies have pivoted towards showing the benefits of faecal microbiota transplant (FMT) as an alternative to antibiotics, in cases of recurrent or refractory Clostridium difficile superinfection or as a preventative prophylactic measure..$^{22-24}$

To the best of our knowledge, no previous studies have explored the public's understanding of microbiota and its influencing factors, in the UAE. It is essential to determine the knowledge, attitudes and practices (KAP) of the population regarding microbiota and its influencing factors to explore the baseline knowledge to allow for targeted awareness campaigns to shed light on the significance of the issue. Thus, this study aims to explore the KAP of the UAE's population regarding microbiota and the factors affecting its composition, especially probiotics and antibiotics.

\section{METHODOLOGY}

\section{Study design and target population}

A descriptive, cross-sectional study was conducted to assess the KAP of the UAE population on the role of microbiota in disease and the factors affecting its composition. The inclusion criteria consisted of UAE citizens and residents, aged 18 years and above, who spoke either English and/ or Arabic as those are the only languages spoken by the researchers in the study. Visitors to the UAE and tourists were excluded from the study. Non-probability, convenience sampling was used to recruit participants from public venues in the three largest cities of the UAE (Abu
Dhabi, Dubai and Sharjah) between the months of ${ }^{25}$ May and September 2018. These cities are the cultural and commercial hubs of the country and comprise most of the UAE population. A minimum sample size of 385 was calculated based on $5 \%$ marginal error and $50 \%$ prevalence using the following formula: $n=\frac{4 p(1-p)}{S E^{2}}$, where $\mathrm{n}=$ sample size, $\mathrm{p}=$ expected prevalence and $\mathrm{SE}=$ sampling error.

\section{Questionnaire development}

A self-administered questionnaire was developed after reviewing the literature and multiple international studies. ${ }^{7}$ 20 26-28 The questionnaire was developed in English and translated into Arabic. It consisted of 44 questions divided into four sections dealing with: demographics (4 questions), knowledge of microbiota (29 questions) and attitudes and practices toward microbiota (11 questions). It contained 5-item Likert scales, true and false, and multiple-choice questions. Before proceeding with data collection, standardisation sessions were held, through which the researchers agreed on a consistent and uniform method of data collection.

\section{Patient and public involvement}

Members of the public were involved in the development of the questionnaire and the outcome measures. Prior to the commencement of the survey, the English questionnaire was piloted on 10 individuals and the Arabic version on 7. This allowed for cognitive testing of the questionnaire among members of the public to improve the quality of the questions by helping identify questions, words or phrases that were ambiguous or difficult to understand. Based on the feedback, the questionnaire was modified and edited by the authors to eliminate any ambiguity. Data obtained from the pilot was not included in the data analysis. Following that, members of the public were recruited to take part in the survey. The results of the study will be shared via awareness campaigns and open access publications.

\section{Data collection and analysis}

During data collection, the researchers were available to clarify any doubts the participants had, and the study aims were verbally explained to them. An information sheet was provided stating that completion of the questionnaire indicates agreement to join the study. There were no names or signatures taken to ensure the anonymity of the participants in this study. Confidentiality was maintained as the collected data were only available to the researchers.

Data analysis was conducted via IBM SPSS V.24. The study demographic data included sex, age, level of education and occupation. The normality of the scale data was visualised and statistically tested using the KolmogorovSmirnov test. Comparison of the mean scores among groups was carried out by analysis of variance and Student's t-test, since the parametric assumptions were fulfilled. Additionally, categorical data were outlined as 
frequencies and percentages and compared using $\chi^{2}$ test. Valid percentages were reported to account for missing data. Correct answers for the knowledge questions were awarded a point, whereas incorrect answers or skipped questions were awarded no points. Five-item Likert scales were collapsed into 3-item scales and awarded 1, 2 or 3 points accordingly when analysing attitudes and practices of probiotics and antibiotics. To assess knowledge, a score was calculated based on the participants' responses. A point was given for either affirming a true statement or disagreeing with a false one, and a total score was calculated. Accordingly, participants who achieved total scores of $>66 \%, 33 \%-66 \%$ and $<33 \%$ were classified into groups of 'good', 'average' and 'poor', respectively. The same scoring system was used in assessing respondents' attitudes and practices. To identify the significant predictors of microbiota and probiotic knowledge, stepwise multiple linear regression (MLR) was performed. The variables associated with the dependent variable, with a $p$ value of $\leq 0.05$, were entered in the model. Prior to performing the analysis, assumptions of MLR were tested. A $p$ value of $\leq 0.05$ was considered to be statistically significant. The methodological quality of this study was assessed using Strengthening the Reporting of Observational Studies in Epidemiology Scale.

\section{RESULTS}

\section{Demographics}

Out of 480 questionnaires distributed, a total of 450 questionnaires were completed by respondents, yielding a response rate of $93.8 \%$; however, 31 responses were omitted secondary to incompletion or missing data. Hence, 419 questionnaires were analysed. More than half of the participants were female $(58.7 \%, \mathrm{n}=246)$ and almost half were less than 30 years of age $(45.2 \%, \mathrm{n}=187)$. With regards to educational background, most of the participants were university graduates $(51.0 \%, \mathrm{n}=213)$. Nearly a fifth of the sample $(19.4 \%, \mathrm{n}=81)$ were healthcare professionals (HCPs) from various backgrounds, including doctors, nurses, pharmacists, etc (table 1).

\section{Knowledge of microbiota}

$76.6 \%(\mathrm{n}=321)$ of the participants were able to correctly define microbiota as 'living bacteria inside a human body'. However, less than a third (29.3\%, n=94) of those who defined microbiota correctly had good basic understanding on the topic and more than half $(54.5 \%$, $\mathrm{n}=175$ ) had average knowledge. There was a significant difference in knowledge between those who defined microbiota correctly and who did not $(\mathrm{p}<0.001)$. Those who defined microbiota incorrectly were 6.2 times (95\% CI 2.62 to 14.69 ) more likely to have poor or average knowledge when compared with those who defined it correctly. 52.2\% $(\mathrm{n}=218)$ of the participants believed that having any bacteria in the nose is dangerous; additionally, $62.8 \%(\mathrm{n}=263)$ believed that having bacteria in the intestines will lead to diarrhoea
Table 1 Demographic distribution of the participants

\begin{tabular}{ll}
\hline Demographics & $\mathbf{n}(\%)^{*}$ \\
\hline Sex & $173(41.3 \%)$ \\
\hline Male & $246(58.7 \%)$ \\
\hline Female & \\
Age (years) & $187(45.2 \%)$ \\
\hline $18-29$ & $80(19.3 \%)$ \\
\hline $30-39$ & $73(17.6 \%)$ \\
\hline $40-49$ & $74(17.9 \%)$ \\
\hline $50+$ & \\
\hline Level of education & $69(16.5 \%)$ \\
\hline Below university & $136(32.5 \%)$ \\
\hline University student & $213(51.0 \%)$ \\
\hline University graduate & \\
\hline Occupation & $35(8.4 \%)$ \\
\hline Arts & $67(16.0 \%)$ \\
\hline Business & $43(10.3 \%)$ \\
\hline Education & $78(18.7 \%)$ \\
\hline Engineering and IT & $54(12.9 \%)$ \\
\hline Government & $81(19.4 \%)$ \\
\hline Medical field & $60(14.4 \%)$ \\
\hline Others & \\
\hline
\end{tabular}

*Valid percentages to account for the missing data.

(table 2). Most of the participants, across all age groups, had average knowledge regarding microbiota. Only $33.2 \%(\mathrm{n}=62)$ of the $18-29$ years age group, $18.7 \%$ $(n=15)$ of the $30-39$ years age group, $17.8 \% \quad(n=13)$ of the $40-49$ years age group and $13.5 \% \quad(n=10)$ of the above 50 years age group achieved a good knowledge score $(\mathrm{p}=0.004)$ (figure 1$)$.

Regardless of the level of education, most participants showed average knowledge on microbiota; however, university students had slightly better overall knowledge compared with the other groups $(\mathrm{p}<0.001)$ (figure 1$)$. Surprisingly, almost half of the HCPs had average knowledge $(49.4 \%, \mathrm{n}=40)$. There was a significant difference between knowledge of HCPs and non-HCPs $(p<0.001)$ (figure 1). MLR model indicated that being a university student and an HCP are the only significant predictors regarding microbiota knowledge $(\mathrm{p}=0.014$ and $\mathrm{p}<0.001$, respectively).

Pertaining to knowledge of the probiotics, the results showed that most of the population were not aware of the term probiotics $(60.4 \%, \mathrm{n}=252)$; of those who claimed to be, only $38.8 \% \quad(n=64)$ correctly identified probiotics as 'microorganisms'. Educational campaigns and social media were the most frequently reported sources of information on probiotics among the participants (20.8\%, $\mathrm{n}=60 \%$ and $20.4 \%, \mathrm{n}=59$ respectively). Only $22.9 \%(\mathrm{n}=96)$ were aware that antibiotics are not made from probiotics and only $17.4 \%(\mathrm{n}=73)$ recognised that probiotics and 
Table 2 Knowledge of participants regarding microbiota

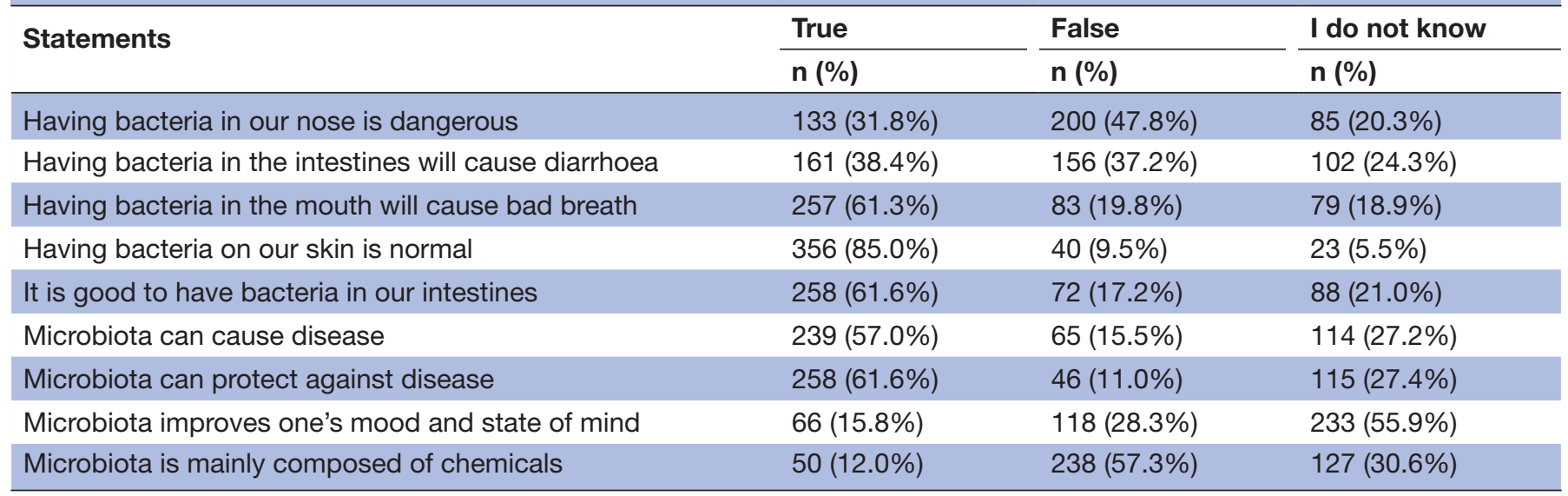

antibiotics can be used together. Only $4.3 \%$ of the participants $(n=18)$ had a good current understanding of probiotics, while the majority had basic information $(62.5 \%$, $\mathrm{n}=262$ ). There was a significant difference between the knowledge of those who claimed to be aware of probiotics and those who were not $(\mathrm{p}<0.001)$. Interestingly, only $9.1 \%(n=15)$ of the respondents who claimed to be aware of probiotics had good knowledge, whereas more than half $(51.5 \%, \mathrm{n}=85)$ had average knowledge. Additionally, non-medical respondents were 9.6 times (95\% CI 3.48 to 26.44 ) more likely to have poor or average knowledge regarding probiotics compared with HCPs. MLR model showed that being a postgraduate and an HCP are the only significant predictors for probiotics knowledge $(\mathrm{p}=0.016$ and $\mathrm{p}<0.001$, respectively).

\section{Practices and attitudes regarding microbiota}

Only $17.8 \%$ of the participants $(n=74)$ reported to have previously consumed probiotics, whereas the majority did not and have no interest in doing so $(44.5 \%$, $n=185$ ). Furthermore, being unaware of the health benefits of probiotics was the most common barrier to taking them $(45.7 \%, \mathrm{n}=187)$. Other barriers included safety concerns $(29.3 \%, \mathrm{n}=120)$ and lack of information on probiotic use $(39.5 \%, \mathrm{n}=161)$ (figure 2 ).

While none of the respondents, with or without a medical background, demonstrated good attitudes and practices towards the use of antibiotics, those with a medical background had better practices and attitudes compared with other occupations $(\mathrm{p}=0.003)$ (figure 3$)$. Alarmingly, $42.4 \% \quad(\mathrm{n}=143)$ and $34.6 \% \quad(\mathrm{n}=28)$ of the non-medical and HCP participants, respectively, admitted they used antibiotics without a prescription. Additionally, 41.2\% ( $n=139)$ of the non-medical participants admitted to stopping the course of antibiotics as soon as they feel better (figure 4). Just over half of the population were unlikely to take faecal pills to treat diarrhoea $(53.2 \%, \mathrm{n}=222)$ secondary to bacterial infections such as $C$. difficile.

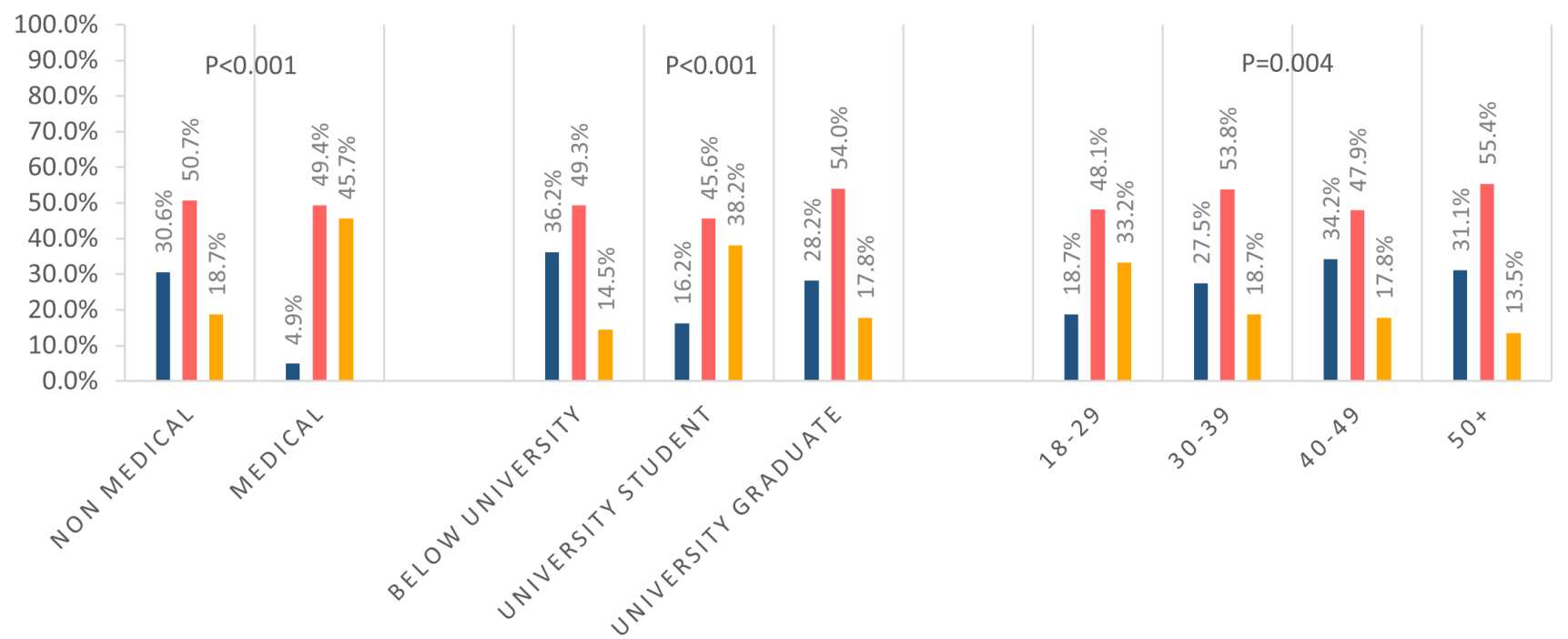

Figure 1 Knowledge of microbiota across the different demographic groups, including occupation, level of education and age. 


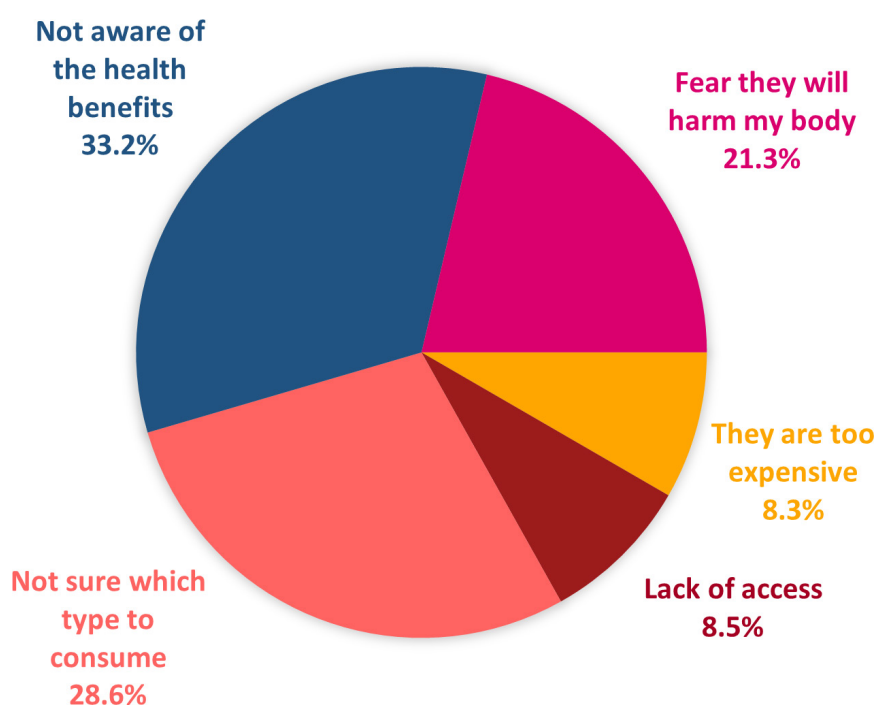

Figure 2 General barriers against probiotics as stated by the participants.

\section{DISCUSSION}

Despite the participants' awareness of microbiota and its basic definition, they lacked good knowledge regarding its role in protecting against disease and boosting one's immunity. More than half of the participants believed that having bacteria in the nose is dangerous and worried that the presence of microorganisms in the intestines may cause diseases such as diarrhoea. This demonstrates that there are misconceptions among people regarding bacteria's role in the human body.

Interestingly, age seems to play an important role in shaping people's knowledge on this topic. Contrary to our expectations, respondents belonging to the older age groups were less versed on the matter when compared with the younger population. This can be attributed to younger people having increased exposure to the internet and social media on a regular basis. Furthermore, university students seemed to have better knowledge, than other educational groups, regarding microbiota.

Since the topic of microbiota is mostly of concern to HCPs and medical students, it is especially important for them to be more knowledgeable on the topic, compared with the general population. Despite our results showing

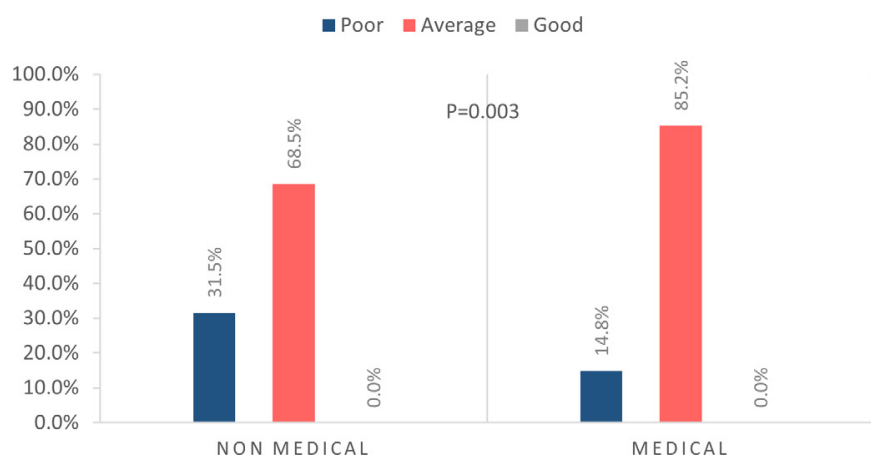

Figure 3 Attitudes and practices of healthcare professionals compared with non-medical participants regarding antibiotics use. that HCPs have better knowledge, it is not significantly higher than that of non-medical personnel.

\section{Probiotics}

As expected, awareness of the term 'probiotics' and what it constitutes was limited. More than $75 \%$ of the participants in our study were unaware of the difference between probiotics and antibiotics and had misconceptions regarding their use. Therefore, it was not surprising that an overwhelming majority $(>80 \%)$ believed that probiotics and antibiotics can never be used together.

Regrettably, almost all participants failed to display good knowledge regarding probiotics, including HCPs. This highlights the importance of educating HCPs on probiotics and the advantages it might provide to their patients. Two meta-analyses reported a reduction in the incidence and duration of respiratory tract infections of viral origin, with probiotic use. ${ }^{29}{ }^{30}$ Additionally, two randomised controlled trials showed that critically ill patients on mechanical ventilation developed substantially less ventilator-associated pneumonia when using probiotics compared with placebo. ${ }^{31} 32$ Probiotics have also shown excellent results in patients with allergies, atopic diseases, asthma and IBD. ${ }^{172533}$

The number of published papers examining the knowledge of the general public regarding probiotics is very limited, with the majority looking at the knowledge of college students and HCPs. In accordance with our study, a study conducted in Saudi Arabia found that the public's knowledge towards probiotics is very limited, just over $25 \% .{ }^{34}$ This is in contrast to a study conducted in Nigeria, assessing knowledge among HCPs, which showed that around $72 \%$ of respondents were aware of probiotics. ${ }^{7}$ In India, a study conducted among college students found that $88.7 \%$ of participants were knowledgeable on probiotics composition. ${ }^{27}$ Furthermore, a study conducted on college students in the Philippines revealed that participants had a good level of knowledge about probiotics and its consumption. ${ }^{35}$ There is an obvious disparity between the knowledge of the general public when compared with HCPs and college students.

Most of our respondents would not consider taking probiotics and were not even willing to learn about them indicating a poor attitude among the UAE society toward probiotics. This finding was similar to an Australian study, where more than $40 \%$ of the participants demonstrated poor behaviours and practices towards probiotics. ${ }^{36}$ However, the participants may have not been aware that they are already consuming probiotics in the form of dairy food such as yoghurt and other types of food like miso, pickles, kimchi and sauerkraut. It would be essential to investigate this to determine if the community actually has negative attitudes towards probiotics consumption.

The use of FMT as a treatment is still being explored, multiple studies have reported positive results in clinical trials. There has been a shift in recent years in the modes of delivery of FMT from oesophagogastroduodenoscopy, nasogastric/jejunal/duodenal tubes, colonoscopy, 


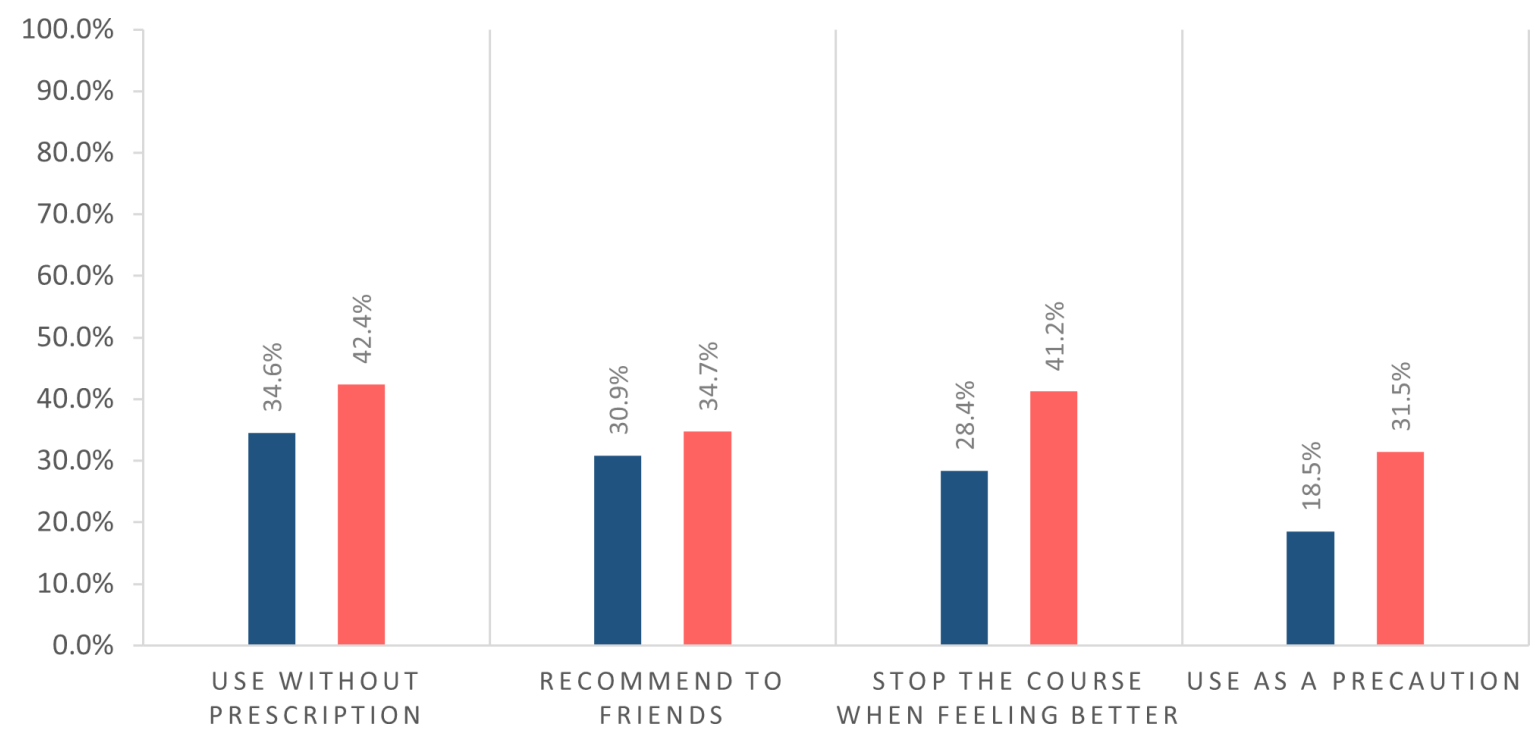

Figure 4 Antibiotics practices of the medical and non-medical participants.

retention enema to oral capsule. ${ }^{37-39}$ However, patients' perspective in using FMT as a treatment modality remains to be further studied to identify the factors that improve attitudes and practices. In our study, more than half of the population were unlikely to take faecal pills, to treat diarrhoea. No other studies seem to have explored the acceptability of FMT in the community; however, the receptivity of probiotic pills in a study conducted in China among patients with Crohn's disease showed that around $80 \%$ of non-refractory patients were willing to seek FMT as a possible cure or to achieve better clinical results. ${ }^{40}$ Another recent study in Germany, investigating general approval of FMT as an alternative treatment for obesity, revealed that more than half of the participants were willing to undergo FMT. $^{41}$

\section{Antibiotics}

Antibiotic misuse can be worrying as it could lead to antibiotic resistance, which is a public health crisis. Since antibiotics interfere with normal microbial homeostasis, it is extremely important to address the general population's unhealthy attitudes and practices towards antibiotic consumption. Alarmingly, not a single respondent in this study exhibited good attitudes nor practices regarding antibiotics, including HCPs. This demonstrates the gravity of the situation and the need for action to be taken towards rectifying this. Inappropriate practices included prophylactic antibiotic use, using antibiotics without a prescription, and not completing the antibiotic course.

Unfortunately, antibiotic misuse is a global concern. Several studies have investigated the public's negative practices and behaviours regarding antibiotics. A study in the UAE's capital, Abu Dhabi, indicated that almost half of the public admitted to taking antibiotics without a prescription. ${ }^{42}$ Additionally, a local study and an Italian one demonstrated that about a third of participants used antibiotics without a prescription. ${ }^{434}$ Moreover, an Indian study demonstrated that around $20 \%$ of medical students abruptly stop the antibiotic course on improvement of their symptoms and give the unused medications to their friends. High rates of improper practices among medical students were also reported despite their adequate knowledge, indicating a disparity in the application of their knowledge. ${ }^{45}$ Furthermore, a study conducted in Jordan found that more than $60 \%$ of respondents admitted to not completing the antibiotic course. ${ }^{46}$

\section{Significance of results and future recommendations}

In the Middle East and North Africa region, the topic of microbiota has not been extensively explored. International studies have recently linked gut microbiota dysbiosis with multiple diseases, including, diarrhoea, obesity, diabetes and IBD. Very recently, a case series from China showed that some patients with COVID-19 demonstrated gut microbial dysbiosis; this further highlights that even during the current pandemic, there is a need to place more emphasis on the topic of microbiota and the factors affecting its composition, which could lead to dysbiosis. ${ }^{47}$ Ongoing research explores methods of using probiotics as a way of restabilising the balance of microbiota to resolve disease. Hence, public knowledge is essential to promote the use of probiotics and decrease antibiotics misuse.

The overall knowledge of the UAE population regarding microbiota and its influencing factors is lacking. This poor knowledge can be attributed to multiple factors, including lack of access to information, inadequate awareness campaigns and the substandard level of knowledge among HCPs. As such, educational and healthpromoting campaigns tackling the benefits of microbiota, its role in conferring immunity against diseases and the main factors affecting its composition would upheave the overall knowledge of the UAE community.

Even though this study did not explore the KAP of the different HCPs, further studies could investigate the 
different backgrounds and educational levels among HCPs, to determine the gaps and areas that need to be focused on through awareness campaigns. Regrettably, the HCPs in our study did not demonstrate sufficient knowledge regarding microbiota. In society, HCPs are viewed as role models of the healthcare system; however, our HCP respondents themselves had bad attitudes and engaged in unhealthy practices involving antibiotics. To rectify this, HCPs must update their knowledge. This can be achieved by attending special courses, workshops and seminars as well as lecture series for professional development on microbiota and its influencing factors to keep up with the current trends in healthcare. Seeking consultation from HCPs regarding appropriate probiotic and antibiotic use should be encouraged. This is especially important as HCPs play a major role in ensuring an appropriate level of knowledge among the general population, ultimately leading to better attitudes and practices. Additionally, further emphasis needs to be placed on the topic of microbiota in medical and health-related schools to ensure that students acquire adequate knowledge for the purpose of educating the general population in the future.

Another way to reach the UAE public is via social media, which was found to be a major source of information regarding probiotics in our study. While internet and social media usage has many benefits, the information shared on such platforms, especially medical, might not always be reliable. Henceforth, care should be taken to monitor and update these resources on a regular basis, to provide accurate knowledge on probiotic forms, health benefits, natural sources and appropriate consumption. Hence, if used correctly, these resources can positively contribute to the society, by promoting health education.

\section{Limitations}

This study used convenience sampling, which might affect the generalisability of the results. Physical mail is not a common mode of communication in the UAE and home visits are not an appropriate method of data collection in this conservative society. Additionally, only the three largest cities, Abu Dhabi, Dubai and Sharjah, were included in the study, which might further affect the generalisability of the results. However, since the UAE is a metropolitan country, we expect the results to be representative of the UAE population. Finally, we did not explore how the difference in socioeconomic status might affect the perception of the participants nor did we investigate the plausible difference in KAP of the local versus the expatriate communities in the UAE.

\section{CONCLUSION}

The overall KAP of the UAE population regarding microbiota and factors affecting it are low. Most participants had wrong perception about the role of microbiota in the body, and their ability to confer illnesses. Additionally, they were not aware about what probiotics comprised of or the health benefits of probiotics. Furthermore, the participants had poor attitudes and engaged in bad practices regarding antibiotics. Hence, it is important to emphasise the role of microbiota in disease and to educate the population, especially HCPs, on the topic.

Acknowledgements The authors thank Dr Amal Hussein from the Department of Family and Community Medicine and Behavioural Sciences at the University of Sharjah for her continuous support throughout the project.

Contributors HJB: contributed to the conception and design of the study, critically revised the manuscript and provided valuable feedback. SFA, HRR and MAA: drafted and tested the questionnaire, participated in data collection, performed the statistical analysis, contributed to writing the manuscript, critically revised the manuscript and provided valuable feedback. SKA: drafted and tested the questionnaire, participated in data collection and performed the analysis.

Funding The authors have not declared a specific grant for this research from any funding agency in the public, commercial or not-for-profit sectors.

Competing interests None declared.

Patient and public involvement Patients and/or the public were not involved in the design, or conduct, or reporting, or dissemination plans of this research.

Patient consent for publication Not required.

Ethics approval This study was approved by the Research Ethics Committee at the University of Sharjah (number: REC-18-01-31-03-S). Information sheet was provided to the participants that stated that completion of the questionnaire indicates agreement to join the study.

Provenance and peer review Not commissioned; externally peer reviewed.

Data availability statement Data are available upon reasonable request.

Open access This is an open access article distributed in accordance with the Creative Commons Attribution Non Commercial (CC BY-NC 4.0) license, which permits others to distribute, remix, adapt, build upon this work non-commercially, and license their derivative works on different terms, provided the original work is properly cited, appropriate credit is given, any changes made indicated, and the use is non-commercial. See: http://creativecommons.org/licenses/by-nc/4.0/.

ORCID iD

Hiba Jawdat Barqawi http://orcid.org/0000-0002-8754-9172

\section{REFERENCES}

1 Sender R, Fuchs S, Milo R. Are we really Vastly Outnumbered? revisiting the ratio of bacterial to host cells in humans. Cell 2016;164:337-40.

2 Sekirov I, Russell SL, Antunes LCM, et al. Gut microbiota in health and disease. Physiol Rev 2010;90:859-904.

3 Duda-Chodak A, Tarko T, Satora P, et al. Interaction of dietary compounds, especially polyphenols, with the intestinal microbiota: a review. Eur J Nutr 2015;54:325-41.

4 Acosta A, Camilleri M. Gastrointestinal morbidity in obesity. Ann N Y Acad Sci 2014;1311:42-56.

5 Qin J, Li Y, Cai Z, et al. A metagenome-wide association study of gut microbiota in type 2 diabetes. Nature 2012;490:55-60. doi:10.1038/ nature11450

6 Hamoudi R, Saheb Sharif-Askari N, Saheb Sharif-Askari F, et al. Prediabetes and diabetes prevalence and risk factors comparison between ethnic groups in the United Arab Emirates. Sci Rep 2019;9:17437. doi:10.1038/s41598-019-53505-7

7 Otuto Amarauche C, Amarauche CO. Assessing the awareness and knowledge on the use of probiotics by healthcare professionals in Nigeria. J Young Pharm 2016;8:53-5.

8 Fao J, Working WHO, Report G. Guidelines for the evaluation of probiotics in food 2002:1-11 https://www.who.int/foodsafety/fs_ management/en/probiotic_guidelines.pdf

9 lannitti T, Palmieri B. Therapeutical use of probiotic formulations in clinical practice. Clin Nutr 2010;29:701-25. doi:10.1016/j. clnu.2010.05.004

10 Sihra N, Goodman A, Zakri R, et al. Nonantibiotic prevention and management of recurrent urinary tract infection. Nat Rev Urol 2018;15:750-76. doi:10.1038/s41585-018-0106-x

11 Shahbazi R, Yasavoli-Sharahi H, Alsadi N, et al. Probiotics in treatment of viral respiratory infections and neuroinflammatory 
disorders. Molecules 2020;25. doi:10.3390/molecules25214891. [Epub ahead of print: 22 Oct 2020].

12 Shenoy A, Gottlieb A. Probiotics for oral and vulvovaginal candidiasis: a review. Dermatol Ther 2019;32:e12970. doi:10.1111/ dth.12970

13 Oak SJ, Jha R. The effects of probiotics in lactose intolerance: a systematic review. Crit Rev Food Sci Nutr 2019;59:1675-83. doi:10.1 080/10408398.2018.1425977

14 Vitellio P, Celano G, Bonfrate L, et al. Effects of Bifidobacterium longum and Lactobacillus rhamnosus on Gut microbiota in patients with lactose intolerance and persisting functional gastrointestinal symptoms: a randomised, double-blind, cross-over study. Nutrients 2019;11. doi:10.3390/nu11040886. [Epub ahead of print: 19 Apr 2019].

15 Zhu R, Chen K, Zheng Y-Y, et al. Meta-analysis of the efficacy of probiotics in Helicobacter pylori eradication therapy. World $\mathrm{J}$ Gastroenterol 2014:20:18013-21. doi:10.3748/wjg.v20.i47.18013

16 Mendoza L. Potential effect of probiotics in the treatment of breast cancer. Oncol Rev 2019;13:422. doi:10.4081/oncol.2019.422

17 Saez-Lara MJ, Gomez-Llorente C, Plaza-Diaz J, et al. The role of probiotic lactic acid bacteria and bifidobacteria in the prevention and treatment of inflammatory bowel disease and other related diseases: a systematic review of randomized human clinical trials. Biomed Res Int 2015;2015:1-15. doi:10.1155/2015/505878

18 Didari T, Mozaffari S, Nikfar S, et al. Effectiveness of probiotics in irritable bowel syndrome: updated systematic review with metaanalysis. World J Gastroenterol 2015;21:3072. doi:10.3748/wjg.v21. i10.3072

19 Sarkar A, Lehto SM, Harty S, et al. Psychobiotics and the manipulation of Bacteria-Gut-Brain signals. Trends Neurosci 2016;39:763-81. doi:10.1016/j.tins.2016.09.002

20 Thursby E, Juge N. Introduction to the human gut microbiota. Biochem J 2017;474:1823-36. doi:10.1042/BCJ20160510

21 Malik B, Bhattacharyya S. Antibiotic drug-resistance as a complex system driven by socio-economic growth and antibiotic misuse. Sci Rep 2019;9:1-2.

22 Mullish BH, Quraishi MN, Segal JP, et al. The use of faecal microbiota transplant as treatment for recurrent or refractory Clostridium difficile infection and other potential indications: joint British Society of Gastroenterology (BSG) and Healthcare Infection Society (HIS) guidelines. Gut 2018;67:1920-41. doi:10.1136/ gutjnl-2018-316818

23 Shen NT, Maw A, Tmanova LL, et al. Timely use of probiotics in hospitalized adults prevents Clostridium difficile infection: a systematic review with meta-regression analysis. Gastroenterology 2017;152:1889-900. doi:10.1053/j.gastro.2017.02.003

24 Goldenberg JZ, Yap C, Lytvyn L, et al. Probiotics for the prevention of Clostridium difficile-associated diarrhea in adults and children. Cochrane Database Syst Rev 2017;12:CD006095. doi:10.1002/14651858.CD006095.pub4

25 Lise M, Mayer I, Silveira M. Use of probiotics in atopic dermatitis. Rev Assoc Med Bras 2018;64:997-1001. doi:10.1590/18069282.64.11.997

26 Chukwu E, Nwaokorie F, Yisau J, et al. Assessment of the knowledge and perception of probiotics among medical science students and practitioners in Lagos state. Br J Med Med Res 2015;5:1239-46. doi:10.9734/BJMMR/2015/13676

27 Sharma R, Gupta S, Gupta D, et al. Awareness and knowledge about probiotics among college students. J Pure Appl Microbiol 2019:13:2201-8.

28 DST P, Huang JH, MHM L. Knowledge, attitudes and practices towards antibiotic use in upper respiratory tract infections among patients seeking primary health care in Singapore. BMC Fam Pract 2016;17:1-9.
29 Hao Q, Lu Z, Dong BR, et al. Probiotics for preventing acute upper respiratory tract infections. Cochrane Database Syst Rev 2011:CD006895. doi:10.1002/14651858.CD006895.pub2

30 King S, Glanville J, Sanders ME, et al. Effectiveness of probiotics on the duration of illness in healthy children and adults who develop common acute respiratory infectious conditions: a systematic review and meta-analysis. Br J Nutr 2014;112:41-54.

31 Morrow LE, Kollef MH, Casale TB. Probiotic prophylaxis of ventilatorassociated pneumonia: a blinded, randomized, controlled trial. Am J Respir Crit Care Med 2010;182:1058-64. doi:10.1164/rccm.200912$18530 \mathrm{C}$

32 Zeng J, Wang C-T, Zhang F-S, et al. Effect of probiotics on the incidence of ventilator-associated pneumonia in critically ill patients: a randomized controlled multicenter trial. Intensive Care Med 2016;42:1018-28. doi:10.1007/s00134-016-4303-x

33 Mennini M, Dahdah L, Artesani MC, et al. Probiotics in asthma and allergy prevention. Front Pediatr 2017;5:165. doi:10.3389/ fped.2017.00165

34 Allah HAA, S. PM. The knowledge and perceptions regarding probiotics among the people of Al-Qassim region, Saudi Arabia. Jhms 2019;2. doi:10.31014/aior.1994.02.03.56

35 Mejia WB, Sheree A, Barrion A. Cronicon knowledge and consumption of probiotic foods of selected students in Laguna, Philippines. EC Nutrition 2019;14:452-9.

36 Khalesi PhD S, Vandelanotte PhD C, Thwaite BSc T, et al. Awareness and attitudes of gut health, probiotics and prebiotics in Australian adults. J Diet Supp/ 2021;18:418-32. doi:10.1080/19390211.2020.17 83420

37 Stallmach A, Steube A, Grunert P. Fecal microbiota transfer: reliable indications, donor screening, and modes of application. Dtsch Arztebl Int 2020;117:31-8.

38 Du C, Luo Y, Walsh S, et al. Oral fecal microbiota transplant capsules are safe and effective for recurrent Clostridioides difficile infection: a systematic review and meta-analysis. J Clin Gastroenterol 2021;55:300-8. doi:10.1097/MCG.0000000000001495

39 Wang J-W, Kuo C-H, Kuo F-C, et al. Fecal microbiota transplantation: review and update. J Formos Med Assoc 2019;118 Suppl 1:S23-31. doi:10.1016/j.jfma.2018.08.011

40 Xu L, Zhang T, Cui B, et al. Clinical efficacy maintains patients' positive attitudes toward fecal microbiota transplantation. Medicine 2016;95:e4055. doi:10.1097/MD.0000000000004055

41 Gundling F, Roggenbrod S, Schleifer S, et al. Patient perception and approval of faecal microbiota transplantation (FMT) as an alternative treatment option for obesity. Obes Sci Pract 2019;5:68-74. doi:10.1002/osp4.302

42 Abasaeed A, Vlcek J, Abuelkhair M, et al. Self-Medication with antibiotics by the community of abu dhabi Emirate, United Arab Emirates. J Infect Dev Ctries 2009;3:491-7. doi:10.3855/jidc.466

43 Abduelkarem AR, Othman AM, Abuelkhair ZM, et al. Prevalence of self-medication with antibiotics among residents in United Arab Emirates. Infect Drug Resist 2019;12:3445-53. doi:10.2147/IDR. S224720

44 Napolitano F, Izzo MT, Di Giuseppe G, et al. Public knowledge, attitudes, and experience regarding the use of antibiotics in Italy. PLoS One 2013;8:e84177. doi:10.1371/journal.pone.0084177

45 Khan A K A, Banu G, KK R. Antibiotic resistance and Usage-A survey on the knowledge, attitude, perceptions and practices among the medical students of a southern Indian teaching hospital. J Clin Diagn Res 2013;7:1613-6. doi:10.7860/JCDR/2013/6290.3230

46 Suaifan GA RY, Shehadeh M, Darwish DA. A cross-sectional study on knowledge, attitude and behavior related to antibiotic use and resistance among medical and non-medical university students in Jordan. African J Pharm Pharmacol 2012;6:763-70.

47 Xu K, Cai H, Shen Y. Management of COVID-19: the Zhejiang experience. Zhejiang Da Xue Xue Bao Yi Xue Ban 2020;49:147-57. 